\title{
Los "Panzudos" Arcaicos Griegos: observaciones sobre un curioso tipo iconográfico
}

\section{The Archaic Greek "Fat-bellied" figures: observations on a peculiar type}

\author{
Manuel Arjona Pérez* \\ Universidad Nacional y Capodistria de Atenas
}

\begin{abstract}
RESUMEN
En el siglo VI a.C. los talleres vasculares y coroplásticos helenos reprodujeron, bien sobre vasos plásticos, bien sobre figuritas de terracota, un tipo iconográfico que representa a un curioso personaje masculino que, desnudo y sonriente, luce un vientre prominente. En este artículo tratamos algunas cuestiones relativas a las variaciones de este tipo iconográfico, la amplia difusión del mismo, la identificación del personaje retratado, sus posibles antecedentes y el contexto de la deposición o consagración de sus representaciones.
\end{abstract}

\section{SUMMARY}

In the $6^{\text {th }}$ century $\mathrm{BC}$, the vascular and cloroplastic workshops of Ancient reproduced, both on plastic vases and terracota figurines, an iconographic type depicting a peculiar nude and smiling fat-bellied male character. This paper deals with aspects related to the variants of this iconographic type, its distribution, the identification of the represented figure, its probable forerunners, as well as the context of the deposition or consecration of its representations.

PALABRAS CLAVES: Figuritas de terracota, vasos plásticos, enanos, demonios, Ptah, patecos.

KEY WORDS: Terracotta figurines, plastic vases, dwarfs, demons, Ptah, pataikoi.

Uno de los tipos iconográficos griegos más interesantes y enigmáticos del siglo VI a.C. (véase Sinn 1983) que fue reproducido tanto en figuritas de terracota como en vasos plásticos, es el denominado

* Quiero agradecer a la 26 ${ }^{\mathrm{a}}$ Eforía de Antigüedades Prehistóricas y Clásicas de Grecia, y más concretamente a la Sra. Michalopoulou, el permiso concedido para que pudiera estudiar personalmente, fotografiar y publicar las figuritas de terracota con forma de panzudos descubiertas en el santuario de Afaia de Egina. "fat-bellied demon", "squatting dwarf" o "crouching dwarf" en la bibliografía especializada en lengua inglesa (Higgins 1954: 20, 56-58, $\mathrm{n}^{\circ}$ 86-94; Hadzisteliou Price 1978: 76; Bell 1981: 15-16 y 129, nº 48 a-b y 49; Dusenbery 1998: 842-843, no XS-239); "grotesque se tenant le ventre", "nain ventru" o "démon ventru" en la bibliografía en lengua francesa (Laumonier 1956: 92, no 212-213; Walter Karydi 1997: 19; Huysecom-Haxhi 2009: 266); "Dickbauch-Dämon", "Dickbäuchiger Zwerg" o "Kourotrophos-Dämon" en la bibliografía en lengua alemana (Rubensohn 1962: 141-142; Schmidt 1994: 99, no. 143, lámina 27g; Hübinger y Menninger 2007: 79 y 238-239, n 199); "demone panciuto" o "divinidad nana e panciuta" en la bibliografía en lengua italiana (Lo Porto 1978: 136;

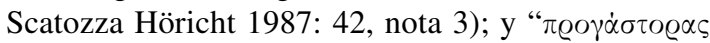

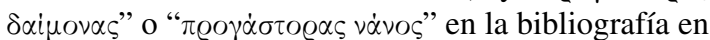
griego moderno (Kokkou-Byridi 1999: 243, n B229; Tsakos 2003: 390). La bibliografía en castellano sobre este tipo iconográfico es, a mi conocer, inexistente.

El tipo iconográfico representa (figs. 1 y 2) una figura masculina desnuda, de cabeza voluminosa, cejas arqueadas, ojos almendrados, nariz ancha, carrillos carnosos y boca pequeña en la que asoma la típica sonrisa arcaica. El cuello es grueso y corto, el cuerpo adiposo y flácido. Los músculos pectorales sobresalen como bultos laxos. El rasgo más llamativo de nuestro personaje es, sin duda, el vientre voluminoso que luce con orgullo. La flacidez muscular se evidencia aún más gracias a los numerosos pliegues de piel que se escalonan sobre la panza y que se patentizan mediante surcos poco profundos, a veces rectos, a veces curvos, que corren paralelos entre sí y que atraviesan horizontalmente la zona abdominal. Los brazos de nuestro personaje se encuentran en contacto con los lados 
del cuerpo, los codos están doblados, los antebrazos se apoyan sobre las costillas, las manos se posan en la barriga. Las piernas del personaje están juntas y flexionadas de tal manera que la parte superior de los muslos entra en contacto con el vientre (figs. 1, 2, 5, 6 y 9). Los órganos sexuales se plasman vagamente, como una protuberancia poco acentuada, aún y cuando en la bibliografía especializada se ha sostenido en alguna ocasión que "le personnage est légèrement ithyphallique" (Laumonier 1956: 92, no 212). En la parte posterior la cabellera del personaje cae hasta cubrir sus omoplatos. En ocasiones se evidencia el peinado mediante surcos horizontales (figs. 3 y 7) o, incluso, mediante una combinación de surcos horizontales y verticales. En este último caso, el resultado es un dibujo ajedrezado. En la espalda del personaje se distingue la línea de la columna vertebral hasta el pliegue interglúteo. Las nalgas son prominentes. En los vasos plásticos, la boca del recipiente emerge de la cúspide del cráneo del personaje. No nos consta ningún caso de vaso plástico con forma de "panzudo" que tenga asas en sus laterales o agujeros para pasar por ellos una cuerda con el fin de transportar o colgar el recipiente. En cuanto a las figuritas de terracota, el

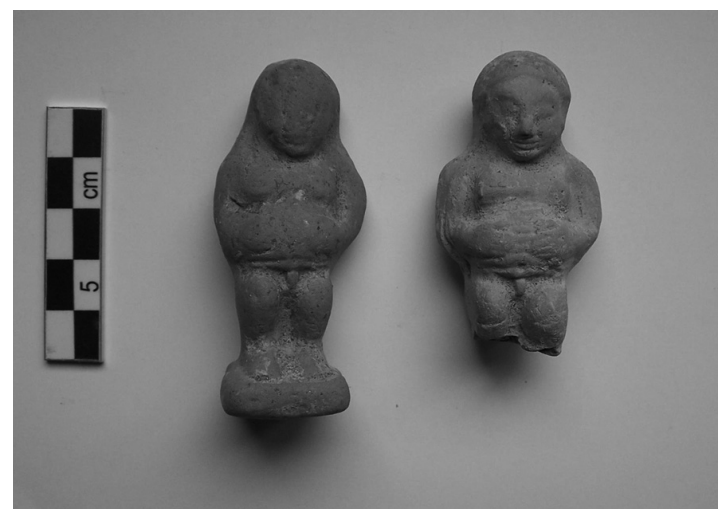

Figura 1. Figuritas arcaicas de terracota representando a "panzudos". Santuario de Afaia (Egina). N ${ }^{\circ}$. Inv. T5229 (izquierda) y T314 (derecha).

personaje se alza sobre una pequeña base rectangular o circular que proporciona estabilidad a la estatuilla.

La altura de las figuritas de terracota suele oscilar entre los 5,5 y los $8 \mathrm{~cm}$. En algunos ejemplares el personaje "panzudo" porta sobre uno de sus hombros a un niño (Bell 1981: 129, nº 48 a, lámina 11) ${ }^{1}$ o un animal (por lo general un mono, Higgins 1954: 57, $\mathrm{n}^{\circ}$ 93, lámina 18; Liepmann 1975: 44, no. T15), o luce sobre la cabeza un petaso (Higgins 1954: 56-57, no. 88, lámina 18), un pilos (Higgins 1954: 58, nº 94 y

\footnotetext{
${ }^{1}$ Eckstein y Legner (Eckstein y Legner 1969: $n^{\circ} 35$ ) se refieren a esta versión del tipo como "Weiblicher Dämon".
}

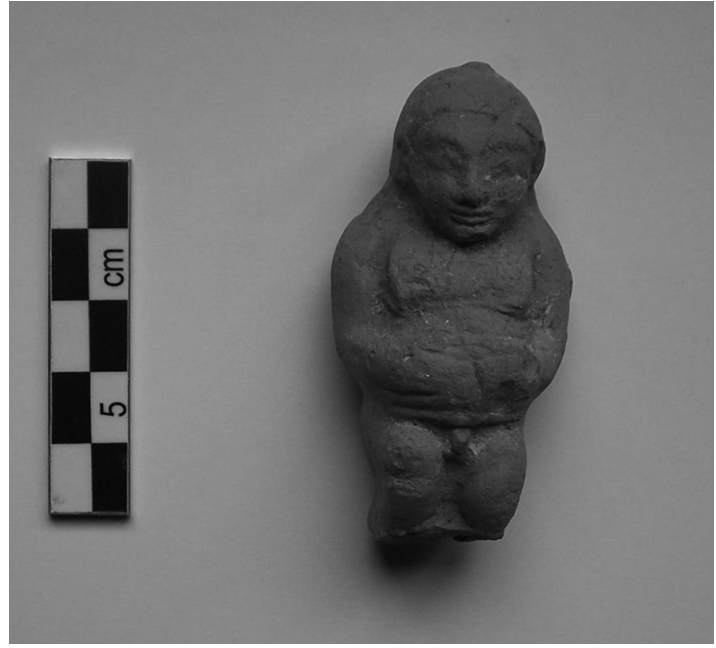

Figura 2. Figurita arcaica de terracota representando a un "panzudo". Santuario de Afaia (Egina). $\mathrm{N}^{\circ} \cdot$ Inv. T12.

lámina 18; Kallipolitis 1966: 78, lámina 77a) o un casco (fig. 5, 6 y 7, véase también Schmidt 1994: 99, no 143, lámina 27g; Spathi 2007: 78, no 90 y 91, lámina 11). Nos consta, incluso, una variante en la que el personaje, además de llevar casco, sostiene un escudo en su mano derecha (Sieveking 1929: 16-17, no. 43, fig. 11), así como una versión, atestiguada en Samos, en la que el personaje porta una bandeja con pasteles sobre la cabeza (Sinn 1985: 151-153, nº 33, lámina 38). Con los elementos complementarios mencionados la figurita puede alcanzar una altura mayor (figs. 8 y 9). Por lo que atañe a los vasos de cerámica que reproducen a nuestro personaje, la altura supera los $13 \mathrm{~cm}$ y puede llegar hasta los 19 cm (Jacopi 1934: lámina 485, 3; Gentili 1951: 310-311, tumba 46, fig. 44, 1; Higgins 1954: 56, nº 86, lámina 18). Las excavaciones arqueológicas han dado igualmente con versiones más complejas, como una figurita de terracota cuya base es una lucerna (Perdrizet 1908: 186, nº 490, ilustración 786a).

Un estudio comparativo de las figuritas de terracota y de los vasos plásticos que reproducen el tipo iconográfico del personaje "panzudo" permite comprobar la considerable diversidad de tipos de arcilla que se utilizaron para modelar los diferentes ejemplares. Igualmente variado es el tipo, el tamaño y la cantidad de desengrasantes minerales que contiene la pasta de las piezas. La calidad de la cocción también es muy dispar de un ejemplar a otro. Por todo esto nos encontramos ante una gran diversificación en lo que se refiere a la consistencia y el color final de las pastas, así como a la aspereza de la superficie de las estatuillas.

Para el moldeado de las figuritas que representan al personaje "panzudo" se requerían dos moldes, uno para la parte frontal de la estatuilla, otro para la parte 
posterior. En ocasiones el coroplasta rellenaba completamente con arcilla los dos moldes, de tal modo que al unirlos resultaba una pieza maciza, compacta. En otros casos el artesano aplicaba simplemente una fina lámina de arcilla sobre sendas matrices de tal manera que al juntarlas quedaba un espacio hueco en el interior de la estatuilla (figs. 3 y 4). Por otro lado, algunas de las figuritas encontradas conservan restos de pintura. Parece que una técnica decorativa muy extendida fue la de cubrir las estatuillas con una capa de pintura blanca que sirviera de fondo para la aplicación de otros colores con los que se plasmaban los detalles: restos de pintura blanca se conservan, de hecho, en el ejemplar encontrado en Samos que porta una bandeja sobre la cabeza (véase Sinn 1985: 151-153, n 33, lámina 38). En cuanto a los vasos plásticos, la técnica de elaboración de las piezas era similar a la de otros vasos arcaicos con forma de animales (monos sedentes, palomas, ciervos), de humanos (figuras femeninas, guerreros, comastas) o de seres híbridos (sirenas) (Dasen 2000: 89).

En lo que atañe a la clasificación y a la identificación del lugar de origen del tipo iconográfico del personaje "panzudo" cabe señalar que Higgins lo incluyó en su Grupo de Afrodita y que lo adscribió, en un principio, a talleres coroplásticos de Rodas y, posteriormente, a talleres coroplásticos de Mileto o Samos (Higgins 1954: 20 y 56-58, nº 86-94; Higgins

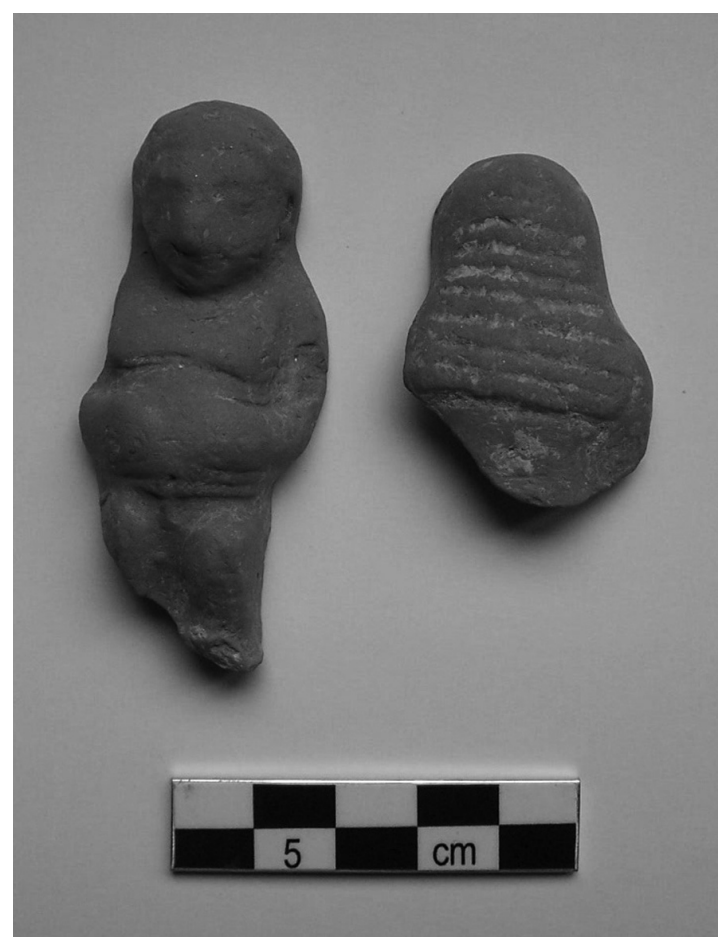

Figura 3. Figurita arcaica de terracota representando a un "panzudo". Santuario de Afaia (Egina). N.Inv. T14.

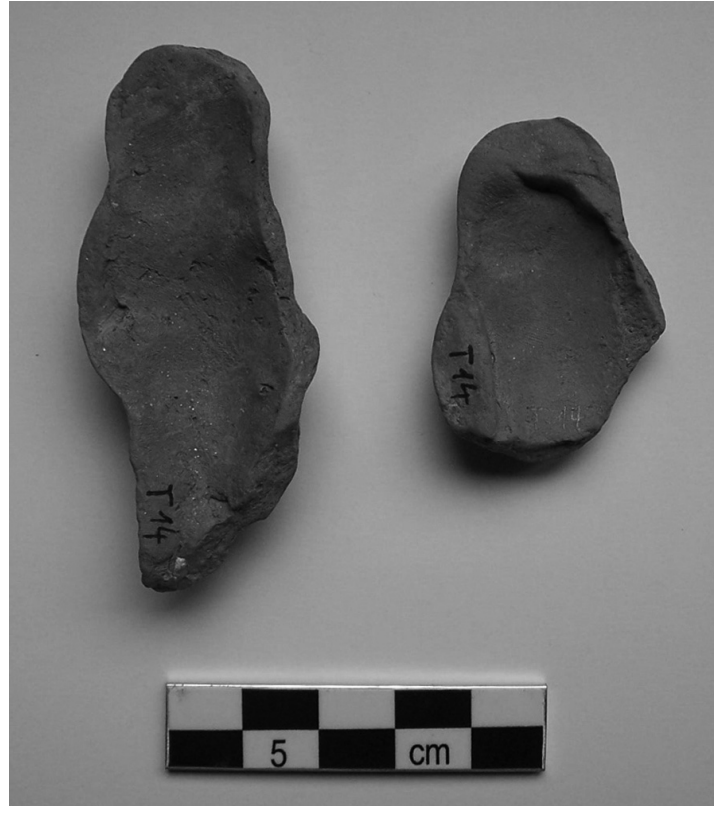

Figura 4. Figurita arcaica de terracota representando a un "panzudo". Santuario de Afaia (Egina). N.Inv. T14.

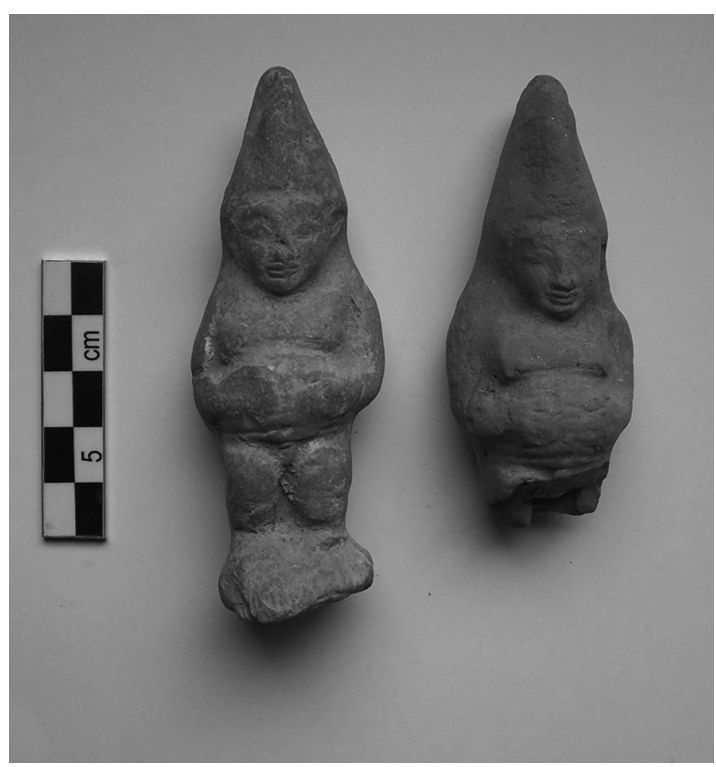

Figura 5. Figuritas arcaicas de terracota representando a "panzudos". Santuario de Afaia (Egina). $\mathrm{N}^{\circ}$. Inv. T18 (izquierda) y T10 (derecha).

1967: 30, 32-34, 36 y 143). A veces en la bibliografía especializada se apunta una adscripción más vaga, considerando como zona de origen la Jonia meridional en general (Bell 1981: 15-16 y 129). En cualquier caso parece ilustrativo el hecho de que muchos ejemplares hayan aparecido en yacimientos arqueológicos de las islas jonias, bien en espacios cultuales (Blinkenberg 
1931: 559-561, lámina 108, nos. 2314-2318 para la acrópolis de Lindos; Jacopi 1933: 297, n 25, fig. 26 para la acrópolis de Camiro; Sinn 1985: 151-153, $\mathrm{n}^{\circ}$ 33, lámina 38 y Walter Karydi 1997: 19 y 26, fig. 9, para el Heraion de Samos; Tsakos 2003: 390 para el santuario de Ártemis localizado en Pitagoreion de Samos) bien en contextos funerarios (Jacopi 1934, lámina 485, no 3 para la necrópolis de Ialiso y Sinn 1977: 12 y 25 , no. 15 , lámina 5 para la acrópolis de Samos). Asimismo es interesante resaltar que en el Heraion de Samos se encontró una figura de madera, fechada a finales del siglo VII a.C., que presenta semejanzas morfológicas con nuestros personajes "panzudos" y que porta a un niño sobre su brazo izquierdo (Kopcke 1967: 100 y sig., no 3; Brize 1997: 135-136, fig. 20). La aparición del tipo iconográfico plástico del personaje "panzudo" ha sido ubicada en el segundo cuarto del siglo VI a.C. a partir de criterios estilísticos y tras el estudio de los contextos arqueológicos de los ejemplares. Las piezas más recientes datan de finales del siglo VI a.C.

Precisamente porque el tipo iconográfico del personaje "panzudo" estuvo en boga durante unas pocas

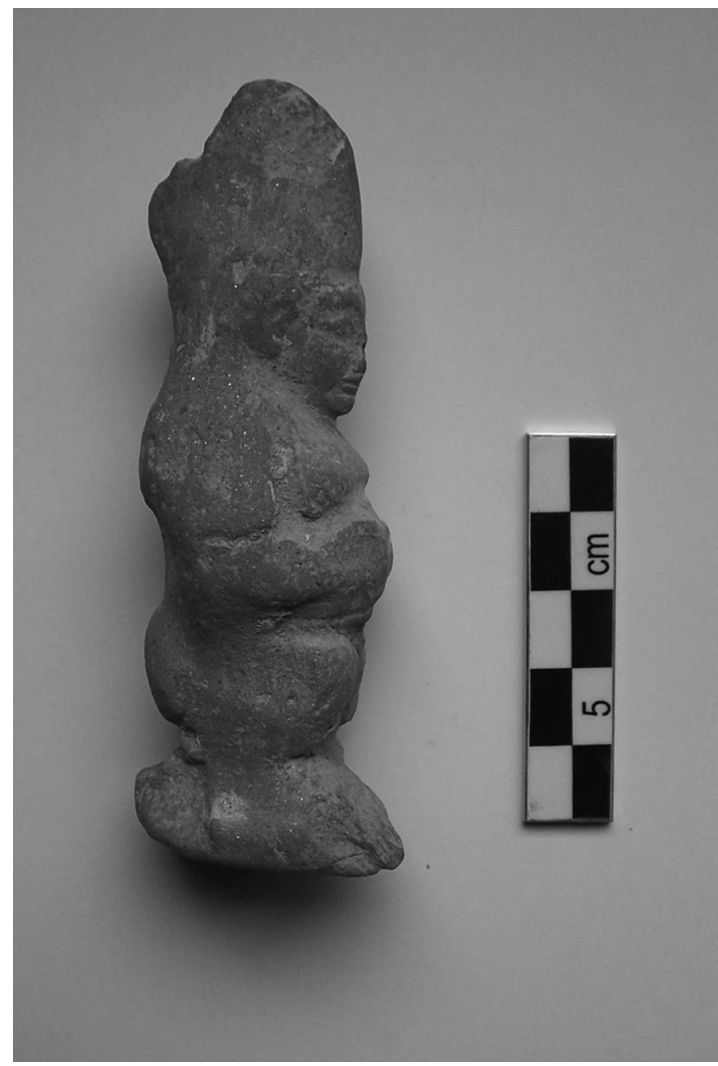

Figura 6. Figurita arcaica de terracota representando a un "panzudo". Santuario de Afaia (Egina). N.Inv. T8. décadas (no parece que la producción de figuritas de terracota y vasos plásticos durase más de ochenta años), resulta sorprendente la amplia difusión y dispersión geográfica de las piezas. Efectivamente, aparte de los ejemplares aparecidos en las islas de Jonia recién citadas, se han encontrado otros en latitudes meridionales como en el yacimiento de Karayeb sito en Fenicia o en el asentamiento de Amizon de Caria, concretamente en el santuario de Ártemis (Kaoukabani 1973: 48, lámina X, 3; Robert y Robert 1983: 64, fig. 35). En el Egeo Central se han encontrado ejemplares en el Delion de Paros, en el santuario de Apolo en Despotikó, en la isla de Reneia frente a Delos, y en Egina, concretamente en una tumba, en el santuario de Apolo en Colonna y en el santuario de Atenea en Afaia (Laumonier 1956: 92, no 212-213, lám. 25; Rubensohn 1962: 141-142, lám. 25, no 34; Kallipolitis 1966: 78, lámina 77; Margreiter 1988: 25 y 69, nº 151, lám. 10; Spathi 2007: 76-78, n ${ }^{\circ}$ 75-92; Kouragios 2009: 124). En Grecia continental se han encontrado figuritas del personaje "panzudo" en el Heraion de Argos, en el santuario de Hera en Peracora, en el Telesterion de Eleusis, en el santuario de Apolo en Delfos y en el santuario de las Musas/Ninfas Libetrias del Helicón (Waldstein 1905: 28, $\mathrm{n}^{\circ}$ 111-113, ilust. 45; Perdrizet 1908: 202, n 652, lám. XXIII, 17; Payne et alii 1940: 254, no 293, lám. 114; Kokkou-Byridi 1999: 243, no B229; Vasilopoulou 2000: 416, $\mathrm{n}^{\circ}$ 22, ilustración $22 \alpha$ $\beta$; Baumbach 2004: 87). Las numerosas excavaciones realizadas en los últimos años en las islas del Egeo Septentrional, en Macedonia y en Tracia también han sacado a la luz una cantidad considerable de figuritas y vasos plásticos que reproducen al personaje "panzudo". En lo que se refiere a contextos funerarios, podemos mencionar los ejemplares hallados en las necrópolis de Samotracia, Acanto, Sindo, Arcontikó de Pella y Aiene (Misailidou 1985: 161-162; KaramitrouMentesidi 1993: 77; Dusenbery 1998: 842-843, $\mathrm{n}^{\circ}$ XS-239; Chrysostomou y Chrysostomou 2007: 116; Karamitrou-Mentesidi 2008: 69 e ilust. 105, 113 y 181; Panti 2008: 23, lám. 2̧). Igualmente han aparecido ejemplares en espacios cultuales como el santuario de Ártemis de Tasos, el santuario ubicado en la acrópolis de Oisime, el santuario arcaico de la colina septentrional de Estagira y el santuario de Poseidón sito en el cabo Poseidi, a unos pocos kilómetros al norte de Mende (Giouri y Koukouli 1988: 370 y 383, ilust. 20; Vokotopoulou 1993: 403 y 410, ilustración 15; Sismanidis 2003: 92, fig. 103, Huysecom-Haxhi 2009: 266-280). También han aparecido ejemplares en determinados asentamientos a orillas del Mar Negro, por ejemplo en Berezán y en Olbia (Kobylina 1970: 32, no 9, lám. 9, 3; Kobylina 1970: 42-43, nº 4, lám. 15, 6). 
La llegada de este tipo iconográfico a Tocra, en la Cirenaica, está atestiguada igualmente por un ejemplar que apareció en un depósito votivo vinculable, probablemente, al santuario local de Deméter (Boardman y Hayes 1966: 154, nº 48 y 49). En Sicilia y en Magna Grecia se ha encontrado un gran número de ejemplares tanto en tumbas como en espacios cultuales: aquí nos limitaremos a mencionar los encontrados en Selinunte, en Gela, en Morgantina, en Siracusa, en Mégara Hiblea, en Catana, en Naxos, en Himera, en Regio, en Tarento y en Cumas (Orsi y Cavallari 1889: 838-839 y 910, lám. VI, 3, 4, 6; Tamponi 1892: 251 (tumba 767); Orsi 1893: 480 (tumba 118); Gabrici 1913: 546-547 y lám. LXXII, 6; Gabrici 1927: 220 y lám. XLI, 2; Gentili 1951: 310-311, fig. 44,1 (tumba 46); Orlandini; 1956: 213 y fig. 10; Vallet 1958: 144; Rizza 1960: 258 y 260, fig. 22, 2, 4 y 13; Lo Porto, 1962: 165-167, fig. 21g y 24; Pelagatti 1964: 154-155 y fig. 16; Allegro 1976: 453, no 23, lámina LXXII, 7; Bell 1981: 15-16 y 129, no 48 a-b y 49, lám. 11; Pelagatti 1984-1985: 280; Scatozza Höricht 1987: 41-42, nº B I, lám. IV); Panvini y Sole 2005: $37, \mathrm{n}^{\circ}$ I.C1 VII, ilustr. IIa.

Aparte de todo esto, varios museos y colecciones privadas cuentan con figuritas de terracota o vasos plásticos que reproducen al personaje "panzudo". En ciertos casos se tiene conocimiento aproximado del lugar de su hallazgo o adquisición: Naucrates, Melos, Egina, Atenas, Tanagra, Lócride Opuntia, Selinunte (Martha 1880: 19, n 69 (53); Martha 1880: 99, n 515 (744); Winter 1903: 213, $\mathrm{n}^{\circ} 1 \mathrm{c}$; Breitenstein 1941: 1415, no 132 y lám. 13; Higgins 1954: 57, no 89 y 93, lám. 18; Higgins 1954: 57, $\mathrm{n}^{\circ}$ 92, lám. 18; MollardBesques 1954: 20, nº B113, lám. XV; Hübinger y Menninger 2007: 79 y 238-239, no 199). En otros casos la procedencia es desconocida (Higgins 1954: 57, $\mathrm{n}^{\circ}$ 91, lám. 18; Schmidt 1994: 99, no 143, lám. 27g).

Se han formulado numerosas hipótesis sobre la identidad del personaje "panzudo", si bien hay un consenso general a la hora de señalar que los antecedentes y/o paralelos más próximos se encuentran en la microplástica egipcia y fenicia de la primera mitad del primer milenio a.C., realizada bien en fayenza (amuletos y figuritas) bien en arcilla (figuritas). Determinados investigadores consideran que el predecesor de los "panzudos" griegos podría haber sido la divinidad egipcia Bes. No obstante, algunos de los elementos más característicos de la iconografía de este dios durante el Tercer Periodo Intermedio y la Época Baja, tales como el bigote y la barba poblada (Velázquez Brieva 2007), constituyen un serio obstáculo cuando se acomete una equiparación entre Bes y nuestro personaje "panzudo". Por ello, la mayoría

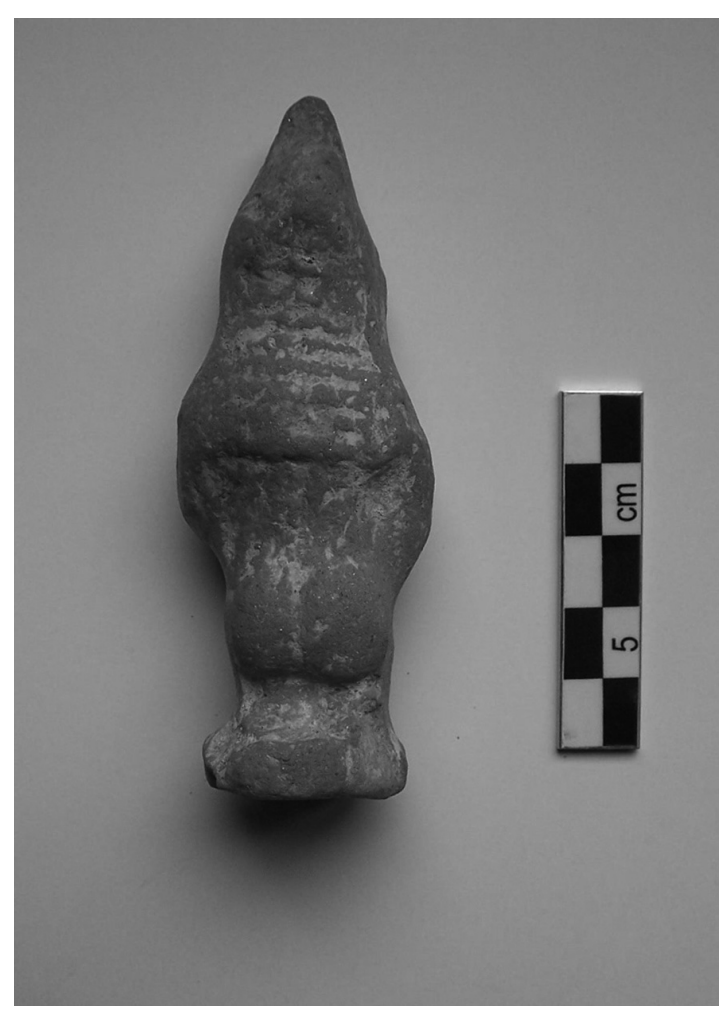

Figura 7. Figurita arcaica de terracota representando a un "panzudo". Santuario de Afaia (Egina). N'. Inv. T8.

de los expertos se decanta últimamente por establecer un paralelismo con las representaciones de otro dios egipcio, en este caso Ptah, que fue venerado en Menfis de manera especial (Morenz 1954: 275-290; Clerc et alii 1976: 117-118 y 124-126; Clerc 1991: 108-113). En escarabeos, amuletos y figuritas de terracota se representa a Ptah como un niño o joven (¿o quizás se trata de un enano?) desnudo, de cabeza voluminosa (y a veces alargada), imberbe, de tripa prominente, piernas arqueadas y nalgas abultadas. En algunos ejemplares, y a diferencia de lo que ocurre con nuestro "panzudo" griego, los brazos de Ptah caen verticalmente a ambos lados del cuerpo, de tal forma que no ocultan el vientre. En otros ejemplares Ptah flexiona sus brazos de tal forma que sus puños se mantienen en la parte alta del abdomen, justo debajo de los pectorales. Dado que Ptah aparece en varias de sus representaciones con serpientes en las manos, se suele considerar que el dios tuvo un carácter ctónico y competencias apotropaicas. Asimismo su apariencia infantil o juvenil ha hecho creer a los expertos que el dios tuvo una relación directa con el ciclo renovador de la Naturaleza. Por extensión también se ha sostenido que fue un dios curotrofo. Además se ha postulado que Ptah estuvo vinculado al trabajo de los metales 
y que fue venerado como protector de los orfebres (Montet 1952; Clerc et alii 1976: 117-118 y 124-126).

La versión fenicia del Ptah egipcio es Pateco o, mejor en plural, los patecos. Heródoto (III, 37) afirma que los marinos fenicios colocaban en la proa de sus naves (¿como mascarón?) reproducciones de estos genios benefactores, los cuales, en opinión del halicarnaseo, se asemejaban a los pigmeos. Heródoto (III, 37) añade que los patecos se parecían a la estatua de Hefesto-Ptah que podía verse en el santuario de dicho dios en Menfis (Hermary 1994).

En muchos yacimientos del Mediterráneo oriental, central y occidental se han hallado representaciones de Ptah-patecos (generalmente sobre amuletos pero también con la forma de figuritas) fechables entre los siglos X y VI a.C. Como simple muestra representativa aquí nos limitaremos a citar algunos ejemplares encontrados en los yacimientos de Kharayeb y Al Mina de Fenicia (Woolley 1938: 160, n MNN 162, lámina XIV, no. MNN 161; Kaoukabani 1973: 48, lám. IX, 4); en los yacimientos de Amatonte y Kition de Chipre (Clerc et alii 1976: 117-118, 124-126; Clerc 1991: 108-113); en los yacimientos de Cnossos y Fortetsa de Creta (Brock 1957: 83 y 208, nº 924, lám. 59; Stampolidis et alii 1998: 147, $\mathrm{n}^{\circ}$ 261;); en Camiro y en Lindos de Rodas (Blinkenberg 1931: 340-343, $\mathrm{n}^{\circ}$ 1216-1226, lám. 53; Jacopi 1933: 305-306, fig. 39 (IV.10) y fig. 41 (IV), 14620 y 14621); en el Delion de Paros (Rubensohn 1962: 169, lám. 35, 3-4); en una de las tumbas de Lefkandi y en un santuario de Eretria en Eubea (Popham et alii 1980: 224, lám. 235a; Huber 2003, Vol 1: 97-98 (nº 209 - O 212); Vol. 2: lámina 130); y en el Heraion de Argos (Waldstein 1905: 372, no 49, lám. 143), entre otros muchos emplazamientos. También han aparecido representaciones de Ptah-patecos en Sicilia y en la Península Itálica (Tarquinia, Vulci...) así como en Ibiza y la Península Ibérica (Hölbl 1979: 112-118 y 121-125; Fernández y Padró 1986: 15-22; Fletcher 2004) (Fig. 8).

A partir de los casos paradigmáticos recién listados se puede inferir que no les fueron totalmente desconocidas a los griegos de los periodos protogeométrico, geométrico y arcaico las representaciones de personajes "panzudos", desnudos y acuclillados que se plasmaron en las manufacturas de la microplástica egipcia y fenicia. Bien al contrario, estos amuletos y figuritas de Ptah que arribaron a ámbitos helenos gracias a los contactos comerciales establecidos en el Mediterráneo Oriental y Central se consideraron como objetos totalmente apropiados para ser depositados como ajuares funerarios en las necrópolis y (lo que sin duda resulta más interesante) como ofrendas votivas en los santuarios de divinidades griegas. Amén de esto,

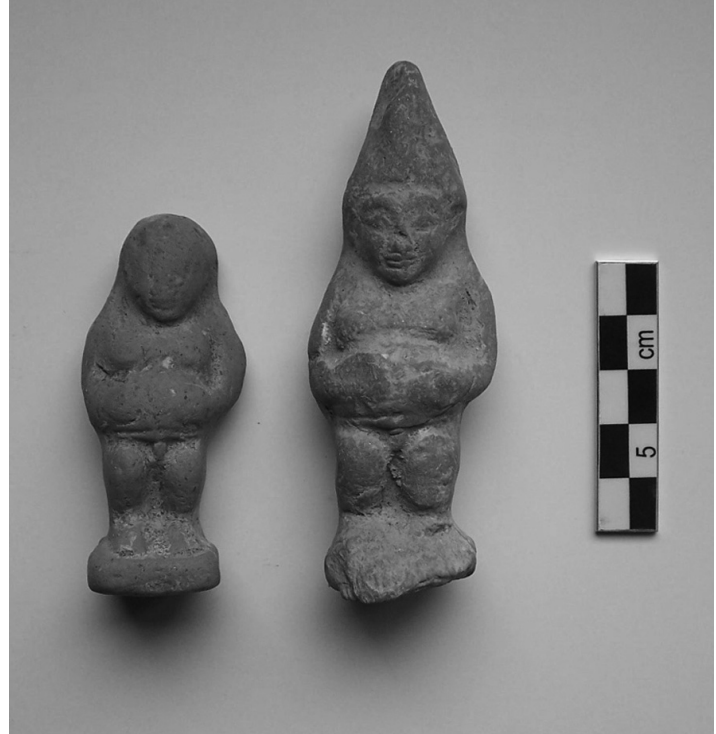

Figura 8. Figuritas arcaicas de terracota representando a "panzudos". Santuario de Afaia (Egina). N·Inv. T5229 (izquierda) y T8 (derecha).

quizás no sea ocioso recordar que en el arte griego arcaico encontramos otras categorías de personajes acuclillados con barrigas y glúteos prominentes. Aquí podríamos mencionar, verbigracia, los comastas que figuraron, principalmente desde el último cuarto del siglo VII a.C., como motivo decorativo tanto en vasos cerámicos como en placas votivas (Seeberg 1971), o que supuestamente sirvieron de modelo para un tipo de vasos plásticos que fue producido fundamentalmente por talleres corintios y que gozó de gran fama durante la primera mitad del siglo VI a.C. (Ducat 1963: 435 y sig.; Amyx 1988: 530-532). Bien es cierto que las diferencias entre nuestros "panzudos" desnudos y los bailarines de comos son numerosas, siendo una de ellas el que los comastas se representaban por lo general vestidos $^{2}$. Sin embargo, tales diferencias no constituyen un obstáculo para que se haya sugerido (Dasen 2000: 89-97; Smith 2010: 14-16) que determinadas divinidades panzudas egipcias, tales como Bes o Ptah, pudieron ser los antecedentes de los comastas. (Fig. 9).

Pero volvamos a nuestros personajes "panzudos" griegos. Como hemos apuntado, en la bibliografía especializada se tiende a sostener que el "panzudo" heleno sería la interpretatio graeca del Ptah egipcio, según algunos investigadores como resultado de una asimilación directa, según otros a través de un proceso indirecto que habría tenido como etapa intermedia

\footnotetext{
${ }^{2}$ Se ha supuesto que las vestimentas con las que se representaban a los comastas estaba acolchonadas, rellenadas o aumentadas con el fin de dar precisamente una apariencia oronda a estos danzantes (v. Smith 2010: 18-23).
} 


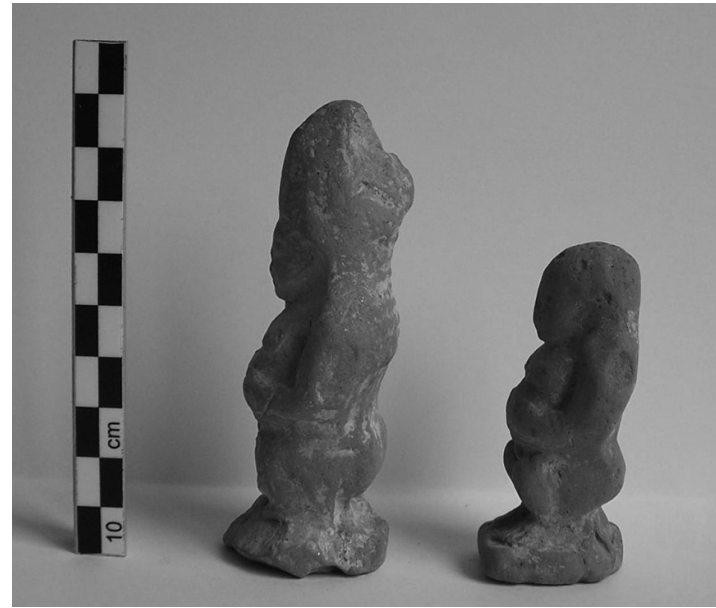

Figura 9. Figuritas arcaicas de terracota representando a "panzudos". Santuario de Afaia (Egina). N. Inv. T8 (izquierda) y T5229 (derecha).

la versión fenicia de los patecos. Para Blinkenberg (1931: 559-561, lámina 108, nos. 2314-2318) y Lo Porto (1978: 136), la aceptación y popularización del tipo iconográfico por parte de los helenos se habría visto facilitada por su equiparación en Rodas con los Telquines, unas divinidades menores que fueron especialmente agasajadas en esta isla y que, tal y como se decía, eran duchas en las artes marítimas y metalúrgicas (tenían por lo tanto funciones afines a Ptah y a los patecos). Bell no comparte esta opinión y postula que los "panzudos" helenos no representan ninguna divinidad helena concreta: inspirándose en las representaciones de Ptah-patecos, los coroplastas helenos se habrían limitado a retocar su iconografía para hacerla más afín a los cánones estéticos griegos, pero manteniendo, eso sí, el trasfondo temático oriental (lo que este investigador llama "eastern subject"). Para Bell, los griegos sabían que en Egipto a las divinidades panzudas se les consideraban como protectores de los niños y de ahí que los propios helenos del periodo arcaico hubieran decidido depositar, a su vez, las figuritas griegas de "panzudos" en tumbas infantiles (Bell 1981: 15-16).

En realidad, el significado simbólico de los personajes "panzudos" helenos ha dado lugar a numerosas hipótesis. Muchos autores, además de Bell, creen en su función como curotrofos, es decir, como cuidadores de niños. Hadzisteliou Price (1978: 76) se adhiere a esta interpretación basándose principalmente en las figuritas de "panzudos" que portan a niños en sus hombros. Ahora bien, la investigadora no excluye la posibilidad de que los "panzudos" hubieran sido considerados como simples humanos y no como seres sobrenaturales. Por su parte, Sinn ha postulado que los "panzudos" representarían a demonios benignos que tenían competencias curotróficas. Según su opinión, la consagración de figuritas de "panzudos" en santuarios se habría realizado en honor de divinidades exclusivamente femeninas, ya fueran estas las titulares de los espacios cultuales o simplemente unas "deidades visitantes" en santuarios de algún dios masculino (Sinn 1983). Diferente es la opinión de Orlandini, para quien "non vi è dubbio che questo demone deve riallacciarsi al cocetto della fecondità" (Orlandini 1956: 213 y fig. 10). Por su parte Karamitrou-Mentesidi (2008: 113) considera que las figuritas de los "panzudos" tuvieron un carácter apotropaico y que la deformidad de estos seres habría servido para conjurar las fuerzas maléficas. Para Orsi y Cavalleri (1889: 838, nota 1), los coroplastas griegos del periodo arcaico adaptaron el prototipo egipcio-fenicio de Ptah-Patecos al gusto heleno sin tener mayores aspiraciones que la de "diventare un grottesco e semplice $\pi \alpha i \gamma v \iota$ v", o lo que es lo mismo, un juguete. En opinión de los investigadores italianos el personaje sería un "dio della toletta", lo que explicaría su presencia en tumbas infantiles y de mujeres. Scatozza Höricht (1987: 42 y nota 3) consideraba insuficiente la interpretación del personaje "panzudo" como un motivo jocoso, como un $\gamma \varepsilon \lambda \tilde{I}_{\alpha} \alpha$. A su parecer, el vientre prominente del personaje y la posición de las manos sobre la panza podrían indicar que el concepto que se quería transmitir con las figuritas

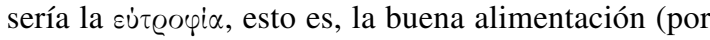
cuanto que abundante) como fuente de salud corporal y de bienestar espiritual.

El lector de esta publicación habrá notado que, a lo largo de la presente aportación, nosotros hemos rehuido la utilización de los sustantivos "enano" o "demonio" cuando nos hemos referido al tipo iconográfico heleno que aquí nos concierne y que, para hablar de este último, hemos optado por los términos "personaje" o "ser" seguidos del adjetivo "panzudo" o bien hemos sustantivado directamente el propio adjetivo "panzudo". La identificación del tipo iconográfico como un enano postulada por ciertos investigadores nos parece, de hecho, poco acertada: en los casos de figuritas en las que se representa a un "panzudo" portando a un niño sobre los hombros, la relación entre el tamaño del "panzudo" y del niño no autoriza a considerar al primero como un enano sino como un adulto plenamente desarrollado. Por otro lado, el vocablo griego daimon (o su castellanización como demonio) quizás pudiera resultar más acertado, pero la designación no deja de ser sumamente problemática, tal y como subraya Burkert (1985: 179-181): aún y cuando se acepte que durante el periodo arcaico esta palabra designaba una divinidad menor de carácter 
benigno, no tenemos la certeza de que a los "panzudos" se les hubiera considerado exclusivamente como representaciones de seres de naturaleza no humana. Barruntamos, de hecho, que el simbolismo de este tipo iconográfico (como el de muchos otros tipos) pudo haber sido muy variado y que, a la hora de colegir su cometido, no debemos limitarnos a constatar exclusivamente su aspecto morfológico sino que hemos de tener muy en cuenta el contexto concreto de su deposición o consagración en una tumba o en un santuario determinado. La identificación del personaje "panzudo" como un curotrofo resulta convincente cuando se le representa portando un niño, pero cuando se le representa en solitario y sin ningún otro elemento complementario surgen dudas mayores. Al hilo de esta cuestión cabe apuntar que las figuritas de "panzudos" sin ningún añadido que han aparecido en tumbas infantiles podrían haber sido simples juguetes con los que los niños enterrados habrían jugado en vida, sin descartar tampoco la posibilidad de que dichas figuritas hubieran sido adquiridas por los dolientes después del fallecimiento del niño para que fueran compañeros afables del pequeño difunto en su viaje al Hades. De darse esto último, entonces los "panzudos" habrían tenido una faceta no solo curotrófica sino también ctónica, similar a la que (se supone) tuvo Ptah.

Por otro lado, para los "panzudos" que no portan a un niño en sus hombros pero que fueron consagrados en determinados santuarios de Deméter y Kore (como ejemplo citaremos el santuario de las diosas emplazado en Eleusis) quizás debamos inferir la misma función de veladores de la infancia que ostentaban las divinidades titulares de dichos santuarios o de sus paredroi. Esta conjetura parece especialmente razonable en aquellos casos en los que los propietarios o propietarias de los espacios de culto tenían un campo de acción muy concreto y limitado, relacionado directamente con la curotrofía: verbigracia, las Musas/Ninfas Libetrias en el Helicón ${ }^{3}$. Por el contrario, difícilmente podemos atribuir una connotación curotrófica al "panzudo" que apareció en el santuario extraurbano mendio de Poseidón, en el cabo Poseidi de la Calcídica. En efecto, a pesar de que al dios del mar se le adjudicó el epíteto Patroos o Fratrios en determinadas zonas de Grecia (por ejemplo en Tesalia, en concreto en Dolique y en Pitoion, Rakatsanis y Tziafalias 2004: 83 y 92), el cuidado de los niños no fue una de las funciones o competencias de Poseidón. El Poseideion de Mende se erigió con la intención manifiesta de señalar un accidente geográfico que resultaba básico como pun-

\footnotetext{
${ }^{3}$ De las informaciones de Pausanias (IX, 34, 4) se desprende la "especialización" de las Musas o Ninfas Libetrias como divinidades protectoras de las madres y de sus retoños.
}

to de referencia para los marineros que surcaban las aguas del Golfo Térmico. El propio santuario constituyó una escala relevante en las rutas marítimas que comunicaban los centros de producción de cerámica del Egeo centro-oriental con los asentamientos del golfo. Por ello, resulta tentador pensar que el oferente que consagró la figurita del "panzudo" en el Poseideion mendio la depositó creyendo que el personaje reproducido, como los patecos fenicios, era un genio benigno estrechamente relacionado con la navegación.

Mucho más difícil resulta adivinar el motivo concreto por el cual un oferente decidió consagrar un "panzudo" en el santuario de Hera en Peracora (Payne et alii 1940: 254, n 293, lám. 114). En este santuario se veneró a la Crónida como diosa protectora de los niños y de los jóvenes implicados en rituales de transición, pero también como protectora de los marineros, por lo que la consagración del ejemplar que representaba a un "panzudo" pudo haber tenido relación con cualquiera de las dos competencias de la diosa titular del espacio sagrado ${ }^{4}$. Por su parte, en el santuario de Atenea en Afaia, donde se ha encontrado un buen número de figuritas de "panzudos", algunas de ellas con casco pero otras sin este elemento marcial (Spathi 2007: 76-78, no 75-92), la hija de Zeus fue venerada, según ha evidenciado Sinn, como una diosa curotrófica, aunque también como una divinidad guerrera y como protectora de los marineros (Sinn 1987 y Sinn 1988). Curiosamente no se ha encontrado ningún "panzudo" portando un niño sobre el hombro en Afaia. La pregunta que lógicamente se plantea es si debemos identificar a los "panzudos" que están cubiertos con cascos como unos seres curotrofos armíferos, similares a los curetes, o si en ellos debemos ver la representación de unos genios belicosos y/o marítimos.

Otra cuestión que también resulta enigmática es el hecho de que el tipo iconográfico de los "panzudos" estuviese en boga solo durante unas ocho décadas. En lo que atañe al lapso de tiempo relativamente corto en que se produjeron los "panzudos" cabe apuntar que Higgins (1967: 34) ha sostenido que, en general, los tipos pertenecientes al Grupo de Afrodita (para él, manufacturas de origen jónico) quizás dejaron de elaborarse debido a las consecuencias negativas que tuvo la revuelta jónica en las ciudades griegas del Egeo oriental y, por extensión, en sus talleres coroplásticos. Sin embargo, la considerable variedad de arcillas usadas para moldear los distintos ejemplares

\footnotetext{
${ }^{4}$ Aquí no tenemos espacio para tratar por extenso las competencias con las que Hera recibía culto en Peracora, aunque sí queremos subrayar su faceta de protectora de la vida familiar y de los marineros. Para mayores detalles remitimos de manera meramente orientativa a De Polignac (1997), Romero Recio (2000: 10-11) y Larson (2007: 34 -35).
} 
de "panzudos" encontrados a lo largo y ancho del Mediterráneo y del Mar Negro permite inferir que este tipo iconográfico también se elaboró fuera de las islas jonias. En virtud de esta constatación las causas políticas de carácter regional se revelan insuficientes a la hora de justificar totalmente la interrupción de la producción de los "panzudos", por lo que quizás debamos achacar dicha suspensión a un cambio en los gustos de los mercados.

Asimismo es notable que el tipo iconográfico de los "panzudos" no derivase en otros tipos semejantes. Aunque algunos rasgos o atributos de los "panzudos" asoman, efectivamente, en determinados personajes que se representaron durante el periodo clásico y helenístico bajo la forma de figuritas de terracota, resulta aventurado sostener que, desde el punto de vista estilístico, estas últimas estatuillas emanaron directamente de los "panzudos". Al hilo de la cuestión mencionaremos que Sinn (1983: 91) ve un vínculo entre los "panzudos" y los paposilenos, probablemente porque los paposilenos, en la coroplástica, también se representaron acuclillados y con una barriga prominente. Sin embargo, los paposilenos por lo general lucen barba y no tienen las dos piernas juntas como los "panzudos", sino separadas, de tal manera que el vientre descolla entre los muslos. Dicha posición permite, precisamente, evidenciar uno de los atributos más importantes de las representaciones de los paposilenos y silenos, a saber, su miembro viril, por lo general de grandes dimensiones. La acentuación de los órganos sexuales, exponente de la lubricidad desenfrenada de los (papo)silenos, no es observable en los "panzudos", tal y como hemos apuntado. Por otro lado cabe apuntar que, desde mediados del siglo V a.C. y sobre todo en el siglo IV a.C., los talleres coroplásticos helenos produjeron figuritas de terracota que representan a mujeres desnudas, sonrientes, de mejillas carnosas, senos prominentes y vientre extremamente adiposo. En algunos ejemplares las mujeres aparecen acuclilladas, en otros se mantienen de pie. Las manos de estas mujeres no se posan en el abdomen, como ocurre en las representaciones de los "panzudos" arcaicos, sino que, en el primer caso, agarran las rodillas y, en el segundo caso, se extienden a ambos lados del cuerpo (Thompson 1954: 90-91, nº 2, lám. 21; Vafopoulou-Richardson 1991: 41, no 45; Vierneisel-Schlörb 1997: 87 n 262 , lám. 52, 1-3). En fin, en el siglo IV a.C. también se produjeron figuritas que representan a mujeres obesas, pero en este caso vestidas, que ocasionalmente podían portar a un niño en el hombro (Pfisterer-Hass 1989; Kriseleit y Zimmer 1994: 132, no 54/54a).

Concluyamos. Los "panzudos" griegos arcaicos constituyen una muestra más de la permeabilidad, versatilidad y mutabilidad que caracterizaron a las prácticas cultuales y funerarias helenas. Posiblemente inspirado en modelos egipcio-fenicios, este tipo iconográfico alcanzó (temporalmente) una gran popularidad tanto en ámbitos metropolitanos como en ámbitos coloniales griegos. Las zonas en donde se ha recuperado un mayor número de "panzudos" (a saber, las islas del Egeo oriental, septentrional y central, las costas de Macedonia y Tracia, así como Sicilia, sin olvidar la región del Istmo de Corinto) son precisamente aquellas que se caracterizaron por una implicación activa en las actividades marítimas durante el periodo arcaico y/o por su inclusión en amplias redes comerciales de gran dinamismo y con una participación conspicua de agentes fenicios y egipcios. Sin duda la helenización iconográfica del personaje "panzudo" constituyó un factor esencial para que la figura tuviera una buena acogida en los mercados griegos: los coroplastas lograron dotar al "panzudo" con una imagen más acorde al gusto imperante en los asentamientos griegos tras despojar a su supuesto predecesor, Ptah/Pateco, de ciertos detalles orientalizantes y añadirle o acentuar una serie de rasgos característicos de la estatuaria arcaica helena, tales como la forma almendrada de los ojos, la meidiama y el tipo de peinado a nudos.

Ciertamente, no resulta fácil identificar a los "panzudos" con alguna de las numerosas divinidades menores griegas de sexo masculino que fueron objeto de culto local o supra-regional a lo largo del periodo arcaico y que nos son conocidas gracias a escuetas menciones recogidas en las fuentes filológicas y epigráficas. De hecho, la mayoría de las citas relativas a estas deidades secundarias no contienen la más mínima descripción física de las mismas, por lo que cualquier equiparación con la iconografía de los "panzudos" entraña riesgos evidentes. El aspecto afable de los "panzudos", su sonrisa y la comicidad que emana de su fisonomía y de la posición con las que son retratados podrían llevarnos a pensar que estos seres fueron considerados como exponentes coroplásticos de la buena ventura, la opulencia (al menos nutricional) y la prosperidad. Si, además, fueron considerados como genios o daimones benefactores de naturaleza no humana, eso es algo que no podemos asegurar con toda certeza. Determinados detalles, como el hecho de que estos panzudos fueran representados desnudos, no implican necesariamente que nos hallemos ante personajes de condición divina (esta misma cuestión ha sido debatida hasta la saciedad en el caso de los kouroi arcaicos de mármol).

La indefinición simbólica de los "panzudos" permitió su deposición y consagración en distintos contextos, tanto en tumbas de mujeres como en tumbas infantiles, tanto en santuarios de divinidades masculinas como en 
santuarios de divinidades femeninas. En ciertos casos, cuando el oferente, a la hora de depositar una figurita de un "panzudo", quería expresar un mensaje concreto y hacerlo especialmente patente, tenía a su disposición la posibilidad de adquirir una versión del tipo iconográfico que luciese un elemento suplementario acorde con el objetivo deseado: un niño o un mono sentado en el hombro, una bandeja con productos sobre la cabeza, un casco... No obstante, estos añadidos (que no presentan una gran variedad) plantean nuevas cuestiones interpretativas. Así, cabría preguntarse en qué medida el "panzudo" de Múnich, con su casco y su escudo, bien es cierto, pero semejante a todos sus congéneres en lo concerniente a su rebosante adiposidad, pudo haber sido considerado seriamente como una verdadera divinidad militar, ducha en la batalla, o en todo caso como un ejemplo modélico de guerrero.

Por último es interesante apreciar que los personajes "panzudos" no fueron representados en poses diferentes a la de en cuclillas. Dicha circunstancia los diferencia de otros personajes desnudos (como por ejemplo los sátiros/silenos) que fueron retratados en la coroplástica arcaica en posición acuclillada pero que también adoptaron con el paso del tiempo otras poses, ya fuesen de pie o recostadas. Esta persistencia en la representación estática de los "panzudos", unida al hecho de que apenas se les dotó de unos pocos elementos indumentarios (en realidad, solo registramos una pequeña gama de gorros), restringió considerablemente el abanico de posibles variaciones icónicas de nuestros personajes. Por lo tanto no resulta extraño que, a falta de una regeneración sustancial de su imagen (las variantes en el tipo de peinado no pueden considerarse como grandes alteraciones), el interés que despertaban los "panzudos" entre los adquirientes de figurillas se fuera diluyendo paulatinamente, y que otras producciones coroplásticas novedosas, o al menos más versátiles, terminaran por desbancarlos de los mercados.

\section{BIBLIOGRAFÍA}

Allegro, N. 1976: Himera II. Campagne di scavo 1966-1973, Roma.

Amyx, D.A. 1988: Corinthian vase-painting of the archaic period, Berkeley-Los Angeles.

Baumbach, J. D. 2004: The Significance of Votive Offerings in Selected Hera Sanctuaries in the Peloponnese, Ionia and Western Greece, Oxford.

Bell III, M. 1981: Morgantina Studies I. The Terracottas, Princeton.

Blinkenberg, Ch. 1931: Lindos. Fouilles de l'Acropole, 1902-1914, I. Les petits objets, Berlin.
Boardman, J. y Hayes, J. 1966: Excavations at Tocra 1963-1965: The Archaic Deposits I (Annual of the British School at Athens, Supplement 4), Oxford.

Breitenstein, N. 1941: Danish National Museum: Catalogue of Terracottas. Cypriote, Greek, EtruscoItalian and Roman, Copenhagen.

Brize, Ph. 1997: "Offrandes de l'époque géométrique et archaïque à l'Héraion de Samos", J. de La Genière (ed.), Héra. Images, espaces, cultes. Actes du Colloque International du Centre de Recherches Archéologiques de l'Université de Lille III et de l'Association P.R.A.C., Lille, 29-30 novembre 1993 (Coll. C.J.B., 15), Naples, 123-139.

Brock, J. K. 1957: Fortetsa. Early Greek Tombs near Knossos, London.

Burkert, W. 1985: Greek Religion. Archaic and Classical, Oxford.

Chrysostomou, A. y Chrysostomou, P. 2007: "Tं் $\dot{\varphi} \circ$

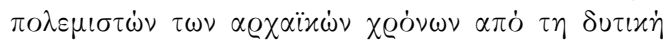

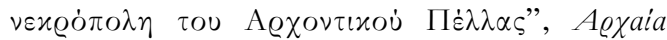
Maxedovia 7, 113-132.

Clerc, G. 1991: "I. Aegyptiaca", V. Karageorghis, O. Picard y Chr. Tytgat (eds.), Études Chypriotes XIII. La nécropole d'Amathonte, tombes 110-385. V. I. Aegyptica. II. Cypriot, Phoenician and Greek seals and amulets. III. Les monnaies. IV. The coins. V. The Inscriptions, Nicosie, 1-157.

Clerc, G., Karageorghis, V., Lagarce, E. y Leclant, J. 1976: Fouilles de Kition. II. Objets égyptiens et éygptisants: scarabées, amulettes et figurines en pâte de verre et en faïence, vase plastique en faïence. Sites I et II, 1959-1975, Nicosia.

Dasen, V. 2000: "Squatting Comasts and ScarabBeetles", G. R. Tsetskhladze, A. J. N. W. Prag y A. M. Snodgrass (eds.), Periplous. Papers on Classical Art and Archaeology Presented to Sir John Boardman, London, 89-97.

De Polignac, F. 1997: "Héra, la navire et la demeure: offrandes, divinité et société en Grèce archaïque", J. de La Genière (ed.), Héra. Images, espaces, cultes. Actes du Colloque International du Centre de Recherches Archéologiques de l'Université de Lille III et de l'Association P.R.A.C., Lille, 29-30 novembre 1993 (Coll. C.J.B., 15), Napoli, 113-122.

Ducat, J. 1963: "Les vases plastiques corinthiens", $B u$ lletin de Correspondance Hellénique 87, 431-458.

Dusenbery, E. B. 1998: Samothrace II. The Nekropoleis. Catalogues of Objects by Categories, Princeton.

Eckstein, F. y Legner, A. 1969: Antike Kleinkunst im Liebieghaus, Frankfurt am Main.

Fernández, J. H. y Padró, J. 1986: Amuletos de tipo egipcio del Museo Arqueológico de Ibiza, Eivissa. 
Fletcher, R. 2004: "Sidonians, Tyrians and Greeks in the Mediterranean: The Evidence from Egyptianising Amulets", Ancient West and East 3, 51-77.

Gabrici, E. 1913: "Cuma”, VV.AA., Monumenti Antichi XXII, Milano-Roma.

Gabrici, E. 1927: "Il Santuario della Malophoros a Selinunte", VV.AA., Monumenti Antichi XXXII, Milano-Roma.

Gentili, G. V. 1951: "Sicilia. III. Siracusa. Scoperte nelle due nuove arterie stradali, la Via di Circonvallazione, ora Viale P. Orsi, e la Via Archeologica, ora Viale F.S. Cavallari”, Notizie degli Scavi di Antichità 5, 261-334.

Giouri, E. y Koukouli, Ch. 1988: “Av $\alpha \sigma \varkappa \alpha \varphi \dot{\eta} \sigma \tau \eta \nu$

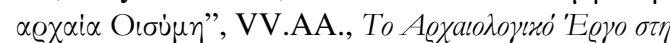

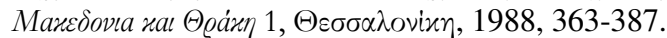

Hadzisteliou Price, Th. 1978: Kourotrophos. Cults and Representations of the Greek Nursing Deities, Leiden.

Hermary, A. 1994: "Patakoi, Pataikoi”, VV.AA., Lexicon Iconographicum Mythologiae Classicae VII, 1, Zürich-München, 201-202.

Higgins, R. A. 1954: Catalogue of the Terracottas in the Department of Greek and Roman Antiquities. British Museum. Volume I. Text. Greek: 730-330 B.C., London.

Higgins, R. A. 1967: Greek Terracottas, London.

Hölbl, G. 1979: Beziehungen der ägyptischen Kultur zu Altitalien, Leiden.

Huber, S. 2003: Eretria XIV. L'Aire sacrificielle au nord du sanctuaire d'Apollon Daphnéphoros, Montreux.

Hübinger, U. y Menninger, M. 2007: Terrakotten der Westgriechen im Akademischen Kunstmuseum der Universität Bonn, Rahden/Westf.

Huysecom-Haxhi, S. 2009: Les figurines en terre cuite de l'Artémision de Thasos. Artisanat et piété populaire à l'époque de l'archaïsme mûr et récent, Paris.

Jacopi, G. 1933: Clara Rhodos, VI-VII. Esplorazione archeologica di Camiro - II, Bergamo.

Jacopi, G. 1934: Corpus Vasorum Antiquarum. Italia. 10. Rodi. Fascicolo II. Museo Archeologico dello Spedale dei Cavalieri di Rodi, Roma.

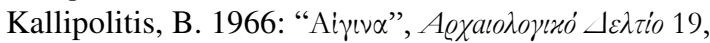
B1, Xeovexd 78.

Kaoukabani, B. 1973: "Rapport préliminaire sur les fouilles de Kharayed, 1969-1970”, Bulletin du Musée de Beyrouth 26, 41-60.

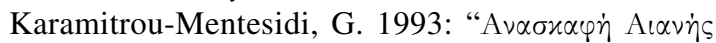

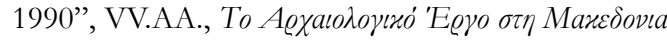

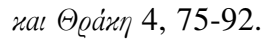

Karamitrou-Mentesidi, G. 2008: Aiani: A guide to the archaeological sites and the museum, Aiani.
Kobylina, M. M. 1970: Svod Arkheologicheskikh Istochnikov. Terrakoty Severnogo Pricěrnomor'ja, Moskva.

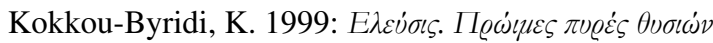

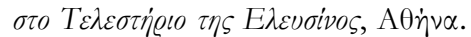

Kopcke, G. 1967: "Neue Holzfunde aus dem Heraion von Samos", Mitteilungen des Deutschen Archäologischen Instituts. Athenische Abteilung 82, 100-148.

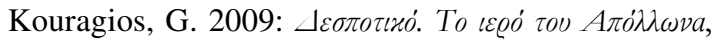
A $\theta \dot{\eta} \nu \alpha$.

Kriseleit, I. y Zimmer, G. 1994: "Katalog”, I. Kriseleit (ed.), Bürgerwelten Hellenistische Tonfiguren und Nachschöpfungen im 19. Jh., Mainz, 83-169.

Larson, J. 2007: Ancient Greek Cults. A guide, New York.

Laumonier, A. 1956: Exploration archéologique de Delos. XXIII. Les figurines de terre cuite, Paris.

Liepmann, U. 1975: Bildkataloge des Kestner-Museums, Hannover. XII. Griechische Terrakotten, Bronzen und Skulpturen, Hannover.

Lo Porto, F. G. 1962: “Tombre arcaiche tarentine con terrecotte ioniche", Bolletino d'Arte 47, 153- 170.

Lo Porto, F. G. 1978: "Le importazioni della Grecia dell'Est in Puglia”, VV.AA., Les cerámiques de Grèce de l'Ést et leur diffusion en Occident. Centre Jean Bérard-Institut Français de Naples. 6-9 Juillet 1976, Paris-Napoli, 131-136.

Margreiter, I. 1988: Alt-Ägina II, 3. Die Kleinfunde aus dem Apollon-Heiligtum, Mainz.

Martha, J. 1880: Catalogue des figurines en terre cuite du Musée de la Société Archéologique d'Athènes, Paris.

Misailidou, B. 1985: Lema no. 253, VV.AA., Livoos.

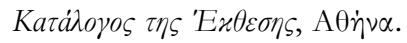

Mollard-Besques, S. 1954: Musée National du Louvre. Catalogue raisonné des figurines et reliefs en terre-cuite grecs, étrusques et romains. I. Époques préhellénique, géométrique, archaïque et classique, Paris.

Montet, P. 1952: "Ptah patèque et les orfèvres", Revue Archéologique 40, 1-11.

Morenz, S. 1954: "Ptah-Hephaistos, der Zwerg. Beobachtungen zur Frage der Interpretatio Graeca in der ägyptischen Religion", VV. AA., Festschrift für Friedrich Zucker zum 70. Geburtstage, Berlin, 275-290.

Orlandini P. 1956: "Sicilia. XVII. Gela. Ritrovamenti vari. I. Molino a Vento. Scoperta di una stipe votiva arcaica", Notizie degli Scavi di Antichità 10, 205-217.

Orsi, P. y Cavallari, F. S. 1889: "Megara Hyblaea, Storia, Topografia, Necropoli e Anathemata", VV. AA., Monumenti Antichi I, Milano-Roma. 
Orsi, P. 1893: "Sicilia. XVI. Siracusa. Relazione sugli scavi eseguiti nella necropoli del Fusco nel dicembre 1892 e gennaio 1893", Notizie degli Scavi di Antichità [s.n.], 445-486.

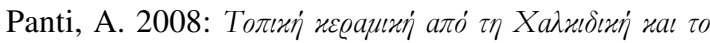

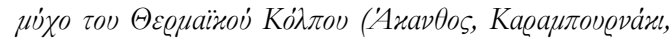

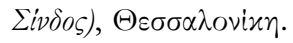

Panvini, R. y Sole, L. 2005: L'acropoli de Gela. Stipi, Depositi o scarichi, Roma.

Payne, H., Dunbabin, T. J., Blakeway, A. A. A. 1940: Perachora. The Sanctuaries of Hera Akraia and Limenia. Excavations of the British School of Archaeology at Athens. 1930-1933. Architecture. Bronzes. Terracottas, Oxford.

Pelagatti, P. 1964: "Naxos. Relazione preliminare delle campagne di scavo 1961-1964", Bolletino d'Arte 49, 149-165.

Pelagatti, P. 1984-1985: "Naxos. Per la storia della ricerca: pagine inedite di Paolo Orsi”, Notizie degli Scavi di Antichità 38-39, 264-300.

Perdrizet, P. 1908: Fouilles de Delphes. V. Monuments figurés, petits bronzes, terres-cuites, antiquités diverses, Paris.

Pfisterer-Hass, S. 1989: Darstellungen alter Frauen in der griechischen Kunst, Frankfurt- Bern-New York-Paris.

Popham, M. R., Sackett, L. H. y Boardman, J. 1980: Lefkandi I. The Iron Age. The Settlement. The Cementeries, Oxford.

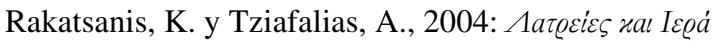

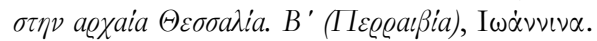

Rizza, G. 1960: "Stipe votiva di un santuario di Demetra a Catania", Bolletino d'Arte 45, 247- 262.

Robert, J. y Robert, L. 1983: Fouilles d'Amyzon en Carie. Tome I. Exploration, histoire, monnaies et inscriptions, Paris.

Romero Recio, M. 2000: Cultos Marítimos y Religiosidad de Navegantes en el Mundo Griego Antiguo, Oxford.

Rubensohn, O. 1962: Das Delion von Paros, Wiesbaden, 1962.

Scatozza Höricht, L. A. 1987: Le terrecotte figurate di Cuma del Museo Archeologico Nazionale di Napoli, Roma.

Schmidt, E. 1994: Martin-von-Wagner-Museum der Universität Würzburg. Katalog der antiken Terrakotten. Teil I. Die figürlichen Terrakotten, Mainz.

Seeberg, A. 1971: Corinthian Komos Vases, London.

Sieveking, J. 1929: "Bericht der Antikensammlungen in München 1918-1924. Museum antiker Kleinkunst", Archäologischer Anzeiger 44, 8-37.

Sinn, U. 1977: Antike Terrakotten. Kataloge der Staatlichen Kunstsammlungen Kassel, Kassel.
Sinn, U. 1983: "Zur Wirkung des ägyptischen Bes auf die griechischen Volksreligion”, D. Metzler, B. Otto y Ch. Müller-Wirth (eds.), Antidoron. Festschrift fur Jürgen Thimme zum 65. Geburstag am 26. September 1982, Kalsruhe, 87-94.

Sinn, U. 1985: "Der sog. Temple D im Heraion von Samos. II. Ein archäologischer Befund aus der nachpolykratischen Zeit. Mit einem Exkurs zum griechischen Bauopfer", Mitteilungen des Deutschen Archäologischen Instituts. Athenische Abteilung 100, 129-158.

Sinn, U. 1987: "Aphaia und die $>$ Aegineten $<$. Zur Rolle des Aphaia-heiligtums im religiösen und gesellschaftlichen Leben der Insel Aigina", Mitteilungen des Deutschen Archäologischen Instituts. Athenische Abteilung 102, 131-167.

Sinn, U. 1988: "Der Kult der Aphaia auf Aegina", R. Hägg, N. Marinatos y G. C. Nordquist (eds.), Early Greek Cult Practice. Proceedings of the Fifth International Symposium at the Swedish Institute at Athens, 26-29 June, 1986, Stockholm, 149-159.

Sismanidis, K. 2003: Ancient Stageira. Birthplace of Aristotle, Athens.

Smith, T. J. 2010: Komast Dancers in Archaic Greek Art, Oxford.

Spathi, M. G. 2007: Studien zur Koroplastik Äginas, Hamburg.

Stampolidis, N. Ch. Karetsou, A. y Kanta A. 1998: Eastern Mediterranean. Cyprus- DodecaneseCrete, 16th-6th Cent. B.C., Heraklion.

Stroud, R. S. 1968: "The Sanctuary of Demeter and Kore on Acrocorinth. Preliminary Report II: 19641965", Hesperia 37, 299-330.

Tamponi, P. 1892: "Sicilia-Sardinia. XIV. MegaraHyblaea. Nuovi scavi della necropoli", Notizie degli Scavi di Antichità [s.n.], 243-254.

Thompson, D. B. 1954: "Three Centuries of Hellenistic Terracottas. I, B and C", Hesperia 23, 72-107.

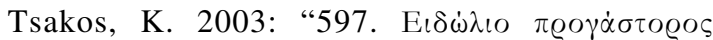

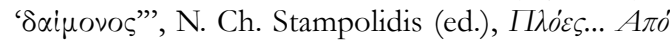

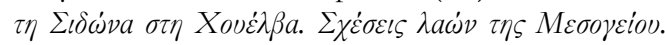

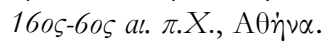

Vafopoulou-Richardson, C. E. 1991: Ancient Greek Terracottas, Oxford.

Vallet, G. 1958: Rhégion et Zancle. Histoire, commerce et civilisation des cités chalcidiennes du détroit de Messine, Paris.

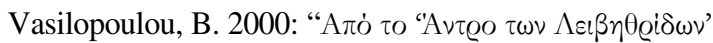

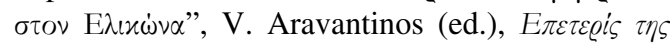

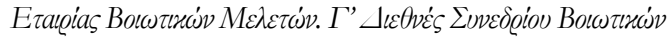

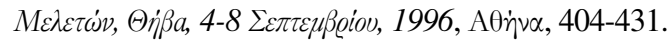

Velázquez Brieva, F. 2007: El dios Bes: de Egipto a Ibiza, Ibiza. 
Vierneisel-Schlörb, B. 1997: Kerameikos XV. Die figürlichen Terrakotten. I. Spätmykenisch bis späthellenistisch, München.

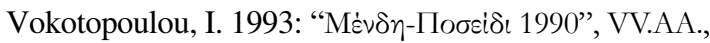

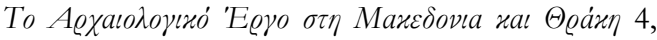
$\Theta \varepsilon \sigma \sigma \alpha \lambda o v i x \eta, 399-410$.

Waldstein, C. 1905: The Argive Heraeum. II. Terracotta figurines, terra-cotta reliefs, vases and vase fragments, bronzes, engraved stones, gems, and ivories, coins, egyptian, or graeco-egyptian, objets, Boston-New York.
Walter Karydi, H. 1997: "Figurines en terre cuite moulées du VIe siècle à Samos", A. Muller (éd.), Le moulage en terre cuite dans l'Antiquité. Création et production dérivée, fabrication et diffusion. Actes du XVIIIe Colloque du Centre de Recherches ArchéologiquesLille III (7-8 déc. 1995), Villeneuve d'Ascq, 13-27.

Winter, F. 1903: Die Typen der Figürlinchen Terrakotten, I. Teil, Berlin-Stuttgart.

Woolley, C. L. 1938: "The Excavation at Al Mina, Sueidia. II", Journal of Hellenic Studies 58, 133170.

Recibido: 13-11-2012

Aceptado: 11-03-2013 